\title{
Trabalhadores e famílias rurais na Região Metropolitana de São Paulo: diversificação dos rendimentos e características familiares em 2008
}

\author{
Nelly Maria Sansigolo de Figueiredo ${ }^{1}$ \\ Bruna Angela Branchi ${ }^{2}$ \\ Angela Antonia Kageyama ${ }^{3}$
}

\begin{abstract}
Resumo: O rural da Região Metropolitana de São Paulo (RMSP) pode ser considerado um caso extremo de rural, altamente integrado com o espaço urbano. O principal objetivo deste trabalho é investigar as condições das famílias rurais na RMSP e contrastar os resultados com as famílias rurais residentes em áreas não-metropolitanas do estado de São Paulo em 2008, focalizando em aspectos relacionados à ocupação, renda, pobreza. Complementarmente, os resultados para 2008 são contrastados com os de 2004. A base de dados é fornecida pela Pesquisa Nacional por Amostra de Domicílios (PNAD) de 2004 e de 2008. As famílias rurais foram classificadas em agrícolas, não-agrícolas e pluriativas e segundo dois cortes geográficos (RMSP e demais áreas rurais do estado de São Paulo). Os resultados indicam que o rural metropolitano é eminentemente não-agrícola, constituído por famílias ocupadas em atividades não-agrícolas, caracterizadas pela maior presença de jovens, maior escolaridade, empregos formais e acesso a itens como água encanada. No entanto, essas famílias estão em piores condições quanto à renda e pobreza comparativamente às famílias rurais não metropolitanas. A proporção pequena de ocupados na agricultura sugere que a proximidade com a metrópole, apesar de oferecer algumas vantagens para as famílias rurais não representa uma integração rural-urbana, uma vez que a ruralidade da família em torno da ocupação agrícola e da agricultura familiar está muito distante desse grupo.
\end{abstract}

Palavras-chave: famílias rurais; desigualdade; Região Metropolitana de São Paulo.

JEL: Jo8; J29.

\footnotetext{
1 Doutora em Economia Aplicada pela Universidade de São Paulo (USP). Professora titular da Pontifícia Universidade Católica de Campinas (PUC/Campinas). E-mail: nsfigueiredo@uol.com.br 2 Doutora em Economia Politica pela Università Degli Studi Di Pavia (Itália). Professora titular da Pontifícia Universidade Católica de Campinas (PUC/Campinas).E-mail: bruna.branchi@puc-campinas.edu.br 3 Doutora em Economia pela Universidade Estadual de Campinas (Unicamp). Professora titular da Pontifícia Universidade Católica de Campinas (PUC/Campinas). E-mail: angela@turing.unicamp.br
} 


\title{
Rural workers and families in the Metropolitan area of São Paulo: earnings diversification and families' characteristics in 2008
}

\begin{abstract}
The rural area of the Metropolitan Region of Sao Paulo city (RMSP) may be considered a singular situation of rural area, highly integrated to the urban center. In this context, the main purpose of this article is to investigate the socioeconomic conditions of the rural families. Aiming to this objective a comparison was undertaken between rural families living in the metropolitan area (RMSP) and those living in other rural areas of the state, with special attention to occupation, income and poverty. Data base comes from the 2004 and 2008 National Household Sample Survey (PNAD) from IBGE (Brazilian Geography and Statistics Institute), considering two samples of the rural families: type of family (agricultural, non-agricultural and pluriactive); and region (the metropolitan rural area RMSP and the other rural areas of the state of São Paulo). The results suggest that most families in the metropolitan rural area have their members occupied in non-agricultural activities. In general, these families are characterized by a stronger presence of youngsters, higher educational level, greater proportion of formal jobs and access to basic public services as piped water. Nevertheless, with respect to income and poverty, these families present worse conditions, when compared to the non-metropolitan rural families. The small proportion of workers engaged in agricultural activities suggests that the proximity with the metropolis does not contribute to a rural-urban integration, given that the rurality of the family, expressed by the agricultural occupation and the family farming, is not a peculiarity of this group.
\end{abstract}

Key-words: rural families; Metropolitan area of Sao Paulo city.

JEL: Jo8; J29.

Introdução

O conceito de rural, como espaço geográfico quase exclusivamente agrícola, modificou-se para melhor descrever a evolução da interação com a área urbana e incluir a diversificação das atividades produtivas nas quais a população rural está ocupada.

As mudanças no rural brasileiro podem ser vistas tanto como consequência da diversificação das atividades econômicas no espaço rural, quanto como resultado do mais fácil acesso ao centro urbano pelo residente rural, que favorece o emprego de trabalhadores rurais no meio urbano (e vice-versa) bem como a adoção, no rural, de hábitos, padrões de consumo, interesses culturais e valores antes considerados "urbanos", caracterizando o que se denomina "novo rural" brasileiro. 
Enquanto no âmbito teórico o conceito de rural tende a abranger outros fatores além do simples conceito de espaço geográfico ${ }^{1}$, a classificação usada pelo IBGE segue um critério administrativo para o qual rural é a área externa ao perímetro urbano, incluindo os aglomerados rurais de extensão urbana, os aglomerados rurais isolados (povoados e núcleos) e a zona rural exclusive os aglomerados rurais. Se de um lado essa definição subestima a população rural, considerando como urbanas cidades e vilas com poucas centenas de residências (Camarano e Abramovay, 1999), por outro lado limita uma realidade complexa a uma classificação meramente administrativa.

Estudos sobre o rural metropolitano são pouco frequentes. Esse espaço sofre de uma invisibilidade, tanto pelos pesquisadores como pelos responsáveis pelas políticas e planejamento econômico das metrópoles brasileiras, como apontado por Santos et al. (2004) em sua pesquisa sobre a Região Metropolitana de Curitiba (RMC). Esses autores concluem que a área rural metropolitana de Curitiba apresenta grande diversidade e complexidade sob os pontos de vista econômico, social, ambiental e cultural e, não obstante as agências de planejamento da RMC reconheçam a presença do rural, a percepção de suas peculiaridade e necessidades específicas é construída em função das demandas urbanas. Os trabalhos de Arraes e Aroni (2008) e Figueiredo e Oliveira e Silva (2008) analisam aspectos demográficos e socioeconômicos das famílias rurais e da PEA rural da Região Metropolitana de Campinas. Estudo sobre a área rural da Região Metropolitana de Porto Alegre focaliza aspectos sócio-ambientais e o papel da área rural metropolitana como reserva de água e de amenidades, cuja preservação condiciona a qualidade de vida no mundo urbano (Pasquetti et al., 2009)

Em geral, percebe-se uma carência de informações sistematizadas sobre o espaço rural metropolitano - como vivem, onde se ocupam e que características específicas distinguem as famílias rurais metropolitanas daquelas residentes em outros espaços rurais. No caso do estado de São Paulo a presença da região metropolitana da capital oferece uma oportunidade interessante para identificar essas especificidades, o que é possível pela comparação de duas realidades "rurais" diferenciadas: o rural da Região Metropolitana de São Paulo (RMSP) e o rural do restante do Estado. Das 19,5 milhões de pessoas da RMSP em 2008, cerca de 875 mil são residentes rurais, número relevante já que corresponde a cerca de $37,4 \%$ da população rural do estado de São Paulo. Quando são observadas as famílias rurais, constata-se que nessa metrópole vivem 250,7 mil famílias rurais, o que representa 35,1\% do total de famílias rurais do estado (PNAD 2008). A presença forte de população rural em áreas metropolitanas não é particularidade do Brasil. Nos Estados Unidos, mais da metade $(50,8 \%)$ da população rural encontra-se em áreas definidas como metropolitanas, segundo o Censo de 2000 daquele país. (Cromartie, 2007)

1 Uma síntese do debate sobre a definição e as características do rural, tanto em economia quanto em sociologia, pode ser encontrada no primeiro capítulo de Kageyama (2008). 
Com relação ao rural das metrópoles norte-americanas, Cromartie e Swanson (1996:31) apontam que a expansão das grandes cidades levou à formação de regiões urbanas espalhadas em que as atividades econômicas se difundiram também nos subúrbios e ao longo de corredores de crescimento, e o desenvolvimento dos sistemas de transporte e de comunicação contribuiu para uma maior integração entre as economias rural e urbana. A economia rural se tornou menos dependente dos recursos naturais e mais diversificada. Como resultado, nessas regiões a distinção entre rural e urbano é mais fraca, existindo um continuum urbano-rural.

O rural da RMSP pode ser considerado um caso extremo, altamente integrado com o espaço urbano, esperando-se, portanto, resultados distintos do rural de outras regiões do estado: menor segregação entre rural e urbano no mercado de trabalho, maior presença de pluriatividade, fluxo intenso de trabalhadores entre os espaços rural e urbano e menores disparidades com relação à qualidade de vida. Espera-se também que as condições da população nessa área sejam diferentes das demais áreas rurais não metropolitanas do estado de São Paulo.

Por entender que "a expansão das grandes cidades localizadas em regiões metropolitanas torna muito "borrada" a distinção entre o rural e o urbano" e..."dificulta as análises", Balsadi (2000:116) excluiu a região metropolitana de seu estudo sobre o emprego rural no estado de São Paulo, que na época contabilizava 10\% da PEA rural. Ao contrário do que sugere Basaldi, acreditamos que no interior das zonas metropolitanas existem diferentes situações de "rural", justificando o presente estudo. Um estudo que apóia essa idéia é o de Morrill et al (1999), que propõem uma classificação das localidades nos Estados Unidos baseada no volume e na direção dos fluxos primários de comutação, identificando como áreas metropolitanas aquelas com elevada urbanização e que funcionam como "centros de trabalho", isto é, com alto fluxo de comutação em direção a elas. Utilizando essa classificação, conseguem identificar muitas áreas rurais independentes, que normalmente caem na categoria "metropolitana" nas estatísticas oficiais, bem como outras áreas rurais que, consideradas independentes nas estatísticas oficiais do Censo, são na verdade altamente conectadas com o "core" metropolitano, em termos de mercado de trabalho, serviços e produtos. Essa diferenciação pode ter impacto significativo na orientação das políticas públicas voltadas para o rural.

Na mesma linha, Plessis et al (2002) mostram a importância da definição de rural na análise socioeconômica da população rural canadense. Em particular, com relação a indicadores como a renda e a pobreza, as populações classificadas como rural/rural (residentes em locais isolados ou em pequenas cidades, sem movimento pendular para os grandes centros) apresentam resultados muito diversos daqueles do rural metropolitano e das cidades maiores. As constatações feitas levam os autores a concluir que é importante diferenciar o rural essencialmente rural (onde o rural está presente 
em todas as suas dimensões - rural como espaço isolado/cidade pequena/ baixa integração com os grandes centros urbanos) daquele em que se fazem presentes outras dimensões, como o rural de centros metropolitanos ou o de grandes cidades, tendo em vista as consequências em termos de políticas públicas. Assim, o estudo do "rural metropolitano" pode trazer evidências sobre suas possíveis especificidades por estar estreitamente integrado (ou não) às áreas urbanas metropolitanas de alta densidade populacional e econômica.

Este artigo tem por objetivo principal investigar as características das famílias rurais contrastando os resultados obtidos pelas famílias da RMSP com aqueles das famílias residentes nas áreas não-metropolitanas do estado de São Paulo em 2008. Para melhor entender as características das famílias rurais foi primeiramente estudado o rural do estado como um todo, classificando as famílias em famílias agrícolas, não agrícolas e pluriativas e depois foram comparados o rural metropolitano e não metropolitano do estado. Outro objetivo do artigo é avaliar diferenças do perfil socioeconômico das famílias rurais, incluindo rendimento, desigualdade da distribuição da renda, pobreza e acesso a bens e serviços básicos segundo o tipo de família, de forma a captar possíveis diferenças entre as famílias classificadas segundo o setor de atividade econômica. Por fim, são estudadas algumas características do chefe da família, incluindo escolaridade, setor de atividade, informalidade, posição na ocupação e rendimento, com o objetivo de identificar possíveis diferenças de acordo com o tipo de família e cortes regionais estudados. Mantendo o foco do estudo na situação de 2008, algumas características das famílias e indivíduos residentes no rural metropolitano serão estudadas também para o ano de 2004 com o objetivo de verificar eventuais mudanças ocorridas no período.

A RMSP é composta por 39 municípios, ocupando $7.944 \mathrm{~km}^{2}$ (a área urbanizada correspondendo a $2.469 \mathrm{~km}^{2}$ ) e com 19,9 milhões de habitantes em 2009, o que resulta numa elevadíssima densidade demográfica, de 2.469 habitantes por $\mathrm{km}^{2}$. Em 2007 a RMSP foi responsável por 57,3\% do PIB paulista.

De acordo com o Censo Agropecuário de 2006, a RMSP possui 4.100 estabelecimentos agropecuários (menos de $2 \%$ do total de estabelecimentos do estado de São Paulo), que ocupam uma área de 112.472 ha. A área média dos estabelecimentos é de 27,4 ha, substancialmente menor do que a média estadual de 73,4 ha. Segundo a mesma fonte, 17.160 pessoas encontravam-se ocupadas nesses estabelecimentos em 31/12/2006, sendo que $56,3 \%$ destas apresentavam algum grau de parentesco com o produtor, o que sugere maior presença da agricultura familiar nesta região, comparativamente à média estadual $^{2}$. Entre as atividades exercidas nos estabelecimentos agrícolas da RMSP, só se destaca a horticultura, que ocupa cerca de 30\% da área agrícola da região e contribui com 19\% no valor da produção hortícola do Estado.

2 Segundo o Censo Agropecuário de 2006, cerca de 910,8 mil pessoas no Estado de São Paulo encontravamse empregadas na agropecuária, das quais $46,5 \%$ apresentavam algum grau de parentesco com o produtor. 
A RMSP tem expressiva participação na produção estadual de alface, espinafre, brócolis, couve, couve-flor, nabo e plantas ornamentais, sendo que nos outros produtos das lavouras e da pecuária sua participação é praticamente nula.

Após esta introdução, o artigo discute aspectos metodológicos da pesquisa, incluindo a definição dos cortes e indicadores utilizados. Em seguida, são apresentados os resultados sobre as características das famílias rurais e acesso a serviços básicos e qualidade da moradia. Continuando a análise exploratória, são descritas algumas características do chefe de família. Finalmente, são destacados, na conclusão do trabalho, os principais pontos de contraste encontrados nesta pesquisa.

\section{Metodologia}

A base de dados é fornecida pelas Pesquisas Nacionais por Amostra de Domicílios (PNAD) de 2004 e 2008, realizadas pelo Instituto Brasileiro de Geografia e Estatística (IBGE).

São estudadas as famílias ${ }^{3}$ rurais e os chefes de família rural do estado de São Paulo, segundo o corte geográfico RMSP e Estado de São Paulo exclusive a RMSP ${ }^{4}$. A definição de rural se baseia na classificação do Censo Demográfico de 2000, que segue a delimitação legal da área urbana à época da realização do censo, não captando, portanto, sua mudança até o período da realização da PNAD. Neste trabalho a população rural inclui os habitantes residentes em aglomerados de extensão urbana residentes fora do perímetro urbano legal, os residentes em aglomerados e núcleos rurais e os residentes na área rural propriamente dita ${ }^{5}$.

3 Para se definir a família, foi construído um Número de Controle da Família, a partir de variáveis de identificação e controle das partes 1, 3 e 4 do Arquivo de Pessoas da PNAD.

4 Pela PNAD é possível desenvolver estudos com base nos seguintes cortes populacionais: Brasil, Grandes Regiões Geográficas, Unidades da Federação e 9 Regiões Metropolitanas (das capitais dos estados de Pará, Ceará, Pernambuco, Bahia, Minas Gerais, Rio de Janeiro, São Paulo, Paraná, e Rio Grande do Sul), mais o Distrito Federal. No estado de São Paulo, além da RMSP, existem outras duas regiões metropolitanas de dimensões menores cujos centros são Campinas e Santos, no entanto, pela própria metodologia da PNAD, não é possível tratar de forma isolada as informações de tais regiões.

5 A classificação do domicílio por situação rural e urbana pela PNAD segue a classificação legal à época da realização do Censo Demográfico, sendo mantida durante o período intercensitário. Dessa forma, os resultados "não captam integralmente a sua evolução, sendo que as diferenças se intensificam à medida que os resultados obtidos se afastam do ano de realização do Censo Demográfico que serviu de marco para a classificação da situação do domicílio.” (PNAD 2008 Notas metodológicas, p. 10). Além da classificação legal, o IBGE utiliza oito classes de localização da população, segundo as características físicas do local do domicílio. Segundo o IBGE a população urbana é formada pelos habitantes das seguintes localizações de área: 1) áreas urbanizadas de cidades ou vila; 2) áreas não-urbanizadas de cidades ou vilas, caracterizadas por ocupação predominantemente de caráter rural; 3) áreas urbanas isoladas, separadas da sede municipal ou distrital por área rural ou por um outro limite legal. (IBGE, 2000. v.7). A população rural é classificada segundo cinco localizações da área: 1) aglomerado de extensão urbana, localizados fora do perímetro urbano, de caráter urbano; 2) povoado, que é o aglomerado rural isolado que oferece um número mínimo de serviços ou equipamentos ; 3) núcleo, que é o aglomerado rural isolado de caráter privado ou empresarial, vinculado a um único proprietário do solo que dispõe de serviços e equipamentos; 4) outros aglomerados que não dispõem de um mínimo de servicos ou equipamentos ; 5) área rural exceto aglomerado. 
Segundo a PNAD 2008 o estado de São Paulo contava com 40.763 .872 habitantes, sendo 19.508.907 na RMSP. A população rural do estado era de 2.343.137 habitantes nesse ano, sendo 876.535 ou 37,4\% com domicílio rural na RMSP.

Além do corte geográfico, foram analisadas as características das famílias rurais do estado de São Paulo segundo três tipos de família rural - agrícola, não-agrícola e pluriativa - segundo critérios utilizados a partir dos estudos do Projeto Rurbano ${ }^{6}$.

As famílias foram classificadas segundo o setor de atividade de seus membros no trabalho principal, de acordo com o Classificação Nacional de Atividade (CNAE) sendo assim constituídas:

* Família agrícola: todos os membros ocupados têm atividade principal na agricultura, incluindo pesca e exploração silvestre;

* Famílias não-agrícolas: todos os membros ocupados têm atividade principal não-agrícola;

* Famílias pluriativas: pelo menos um membro é ocupado em atividade agrícola e pelo menos um membro é ocupado em atividade não-agrícola.

Para o estudo das famílias, são considerados apenas os membros pertencentes ao núcleo familiar, o que exclui os agregados, pensionistas, empregados domésticos e seus parentes residentes no domicílio. A amostra expandida de membros de famílias rurais em 2008 soma 2.337.747 indivíduos, resultado da perda de $0,2 \%$ do total de observações após a eliminação dos indivíduos não pertencentes ao núcleo familiar.

Entre os ocupados estão incluídos os indivíduos que efetivamente trabalharam na semana de referência, bem como aqueles afastados temporariamente do trabalho, os ocupados em atividades de autoconsumo e de autoconstrução. De acordo com os critérios do IBGE, trabalho é qualquer atividade desenvolvida pelos indivíduos, inclusive a de ser empregador (PNAD 2008, Notas Metodológicas).

Justifica-se o foco no trabalho principal como base para definir a tipologia da família tendo em vista seu papel importante para a determinação do rendimento total. Por exemplo, para os ocupados rurais de São Paulo em 2008, cerca de 90\% do total dos rendimentos originam-se do trabalho principal. (PNAD 2008)

6 O Projeto Rurbano teve início em 1996 no Núcleo de Economia Agrícola do Instituto de Economia da Unicamp, reunindo pesquisadores de 11 estados brasileiros voltados à análise das novas relações entre o rural e o urbano. Em 2004 foi publicada uma coleção de 6 livros consolidando os resultados finais do projeto (ver Campanhola e Graziano da Silva, ed., 2004). Informações sobre as diversas etapas do projeto podem ser encontradas em: <http://www.eco.unicamp.br/pesquisa/NEA/pesquisas/rurbano/>. 
Para as famílias são estudadas algumas características demográficas, socioeconômicas e de acesso a bens de consumo e serviços essenciais, segundo os três tipos de famílias - agrícola, não-agrícola e pluriativa e segundo os dois cortes geográficos. Além disso, foram levantadas informações sobre a proporção de jovens (menores de 15 anos) e de idosos (65 anos ou mais de idade) e a razão de dependência, segundo o tipo de família. A escolaridade média é calculada considerando os membros com idade igual ou superior a 15 anos, tendo sido imputado o valor de 17 anos de estudo para o estrato de escolaridade " 15 anos ou mais de estudo" presente na PNAD. As pessoas com menos de um ano de estudo e aquelas com escolaridade não determinada foram agrupadas às sem escolaridade, atribuindo-se valor zero para a escolaridade desse grupo. No cálculo da proporção de indivíduos com carteira assinada por tipo de família, foram analisadas apenas as pessoas ocupadas (incluindo afastados, autoconsumo e autoconstrução) na semana de referência.

Na investigação dos rendimentos, foi necessário eliminar os indivíduos com informações incompletas sobre rendimento, resultando em 2,31 milhões de indivíduos com domicílio rural no estado. Essa amostra exclui, além das pessoas residentes no domicílio que não guardam laços de parentesco com as famílias, aquelas para as quais não se dispõe de informações completas sobre os rendimentos. Para o cálculo do índice de Gini foram eliminadas as famílias com rendimento familiar nulo.

Finalmente, para estudar as condições de conforto, higiene e salubridade no domicílio rural foram calculados os seguintes indicadores: proporção de famílias com água encanada em pelo menos um cômodo; proporção de famílias com instalação sanitária ou banheiro no domicílio ou propriedade; proporção de famílias com rede coletora de esgoto ou fossa séptica; proporção de famílias residentes em domicílios com luz elétrica; proporção de famílias em domicílios com geladeira; e proporção de famílias em domicílios com telefone fixo ou celular. Com esses indicadores foi obtido um índice de nível de vida rural para as famílias, dado pela média desses indicadores, conforme proposto em Kageyama (2008: 172-173).

Um segundo conjunto de informações foi obtido a partir da amostra de chefes de família. A seleção da amostra e o refinamento dos dados visando a obter informações completas das variáveis analisadas resultaram para a PNAD 2008 num número $2 \%$ menor de chefes de família comparativamente ao número de famílias, tanto no rural da RMSP como no resto do estado. Deve-se notar que a análise prioriza o perfil socioeconômico dos chefes ocupados (incluindo os afastados e aqueles ocupados na autoconsumo e autoconstrução), o que justifica a exclusão dos chefes não ocupados da amostra. Para o conjunto de chefes foram investigados a escolaridade, o rendimento no trabalho principal, o setor de atividade, a posição na ocupação e a informalidade, segundo os dois cortes regionais e os três tipos de famílias. 
Com relação ao setor de atividade do chefe, os indivíduos foram classificados segundo a variável V9907, setor de atividade no trabalho principal, uma vez que a variável derivada V4816 publicada pela PNAD 2008 apresenta diferenças de resultados com relação à variável que a gerou 7 . As informações sobre posição na ocupação foram grupadas nas categorias: a) empregados; b) empregadores; c) conta-própria; d) autoconsumo, autoconstrução e empregados sem rendimento. Finalmente, a formalidade no emprego é medida pela proporção de empregados com carteira assinada, referindo-se portanto apenas àqueles chefes na posição de empregados.

As amostras foram obtidas a partir do fator de expansão (peso da pessoa) fornecido pela PNAD, sendo a extração e a análise exploratória dos dados realizadas com o apoio do software SPSS.

\section{Medidas de desigualdade e pobreza}

Os valores dos rendimentos são apresentados em moeda corrente de 2008. A desigualdade da distribuição da renda é medida pelo índice de Gini, de acordo com Hoffmann (1998), tendo sido calculada com base na distribuição dos indivíduos conforme a renda familiar per capita.

A pobreza é medida pela pelos índices $\mathrm{H}$, proporção de pobres; I, razão de insuficiência de renda ${ }^{8}$ e o índice FGT $^{9}$, conforme Hoffmann (1998). Duas linhas de pobreza são calculadas com base no salário mínimo a primeira, correspondente a meio salário mínimo e a segunda, um quarto de salário mínimo. No mês de setembro, época da pesquisa da PNAD, o valor corrente do salário mínimo era de $\mathrm{R} \$$ 415,00 em 2008 e de $\mathrm{R} \$ 260$,00 em 2004, que corrigido pelo INPC corresponde a $\mathrm{R} \$ 315,36$ em valores de setembro de 2008. O indivíduo é classificado como pobre se o rendimento familiar per capita estiver abaixo da linha de pobreza de 1/2 salário mínimo e indigente se o rendimento familiar per capita for menor do que $1 / 4$ de salário

7 Adotou-se o mesmo critério para a PNAD de 2004.

8 A razão de insuficiência de renda $I$ é dada por $I=\frac{1}{k} \sum\left(z-X_{i}\right)$, onde: $X_{i}=$ rendas das pessoas; $k=$ número de pessoas abaixo da linha de pobreza; $z=$ linha de pobreza. Esse índice capta a intensidade da pobreza da população.

9 O índice FGT é uma medida mais completa de pobreza multidimensional, sendo dado por:

$F G T=\frac{1}{\square^{2}} \sum_{1}\left(z-X_{i}\right)^{2}$, onde: $n=$ número de pessoas da população; $X_{i}=$ rendas das pessoas; $k=$ número de pessoas abaixo da linha de pobreza; $z$ = linha de pobreza. Esse índice varia de zero a um, valendo zero quando todas as pessoas têm renda maior que $z$. Esse índice pode ser decomposto quando a população está dividida em grupos (por exemplo, região) sendo que o índice para a população como um todo é dado pela soma ponderada dos índices de cada grupo, tendo como fator de ponderação a participação da população do grupo na população total. 
mínimo ${ }^{10}$. Medidas de pobreza baseadas na renda familiar per capita levam em consideração o papel de redistribuição da renda entre seus membros, exercido pela família.

Deve-se notar que a renda é apenas um dos aspectos que caracterizam a pobreza, haja vista a multidimensionalidade desse fenômeno. Em nosso estudo, são analisadas algumas características família com relação ao acesso a bens e serviços essenciais, na tentativa de explorar outras dimensões da pobreza, que não a estritamente monetária.

\section{Famílias Rurais}

Em 2008, havia 714,6 mil famílias rurais no estado de São Paulo, sendo $35,1 \%$, ou 250,7 mil na RMSP (Tabela 1). Considerando todos os indivíduos dessas famílias, resulta uma população rural de 2.337,7 mil pessoas, sendo 875,5 mil na RMSP. Em 2004, cerca de 718,2 mil indivíduos residiam na metrópole, correspondendo a 33,1\% da população rural do Estado ${ }^{11}$. Portanto, mais de 1/3 das famílias e dos residentes rurais do estado, residentes na RMSP, se encontram em condições bastante específicas, tendo em vista o ambiente urbano e econômico da grande metrópole, que cria oportunidades de participação social e econômica diferenciadas com relação ao restante do estado. Uma inquietação que permeia este trabalho, e que deve ser perseguida neste e em estudos futuros, diz respeito à caracterização do perfil das famílias rurais e dos residentes rurais da metrópole. Uma primeira aproximação sobre as famílias e seus chefes é feita neste trabalho.

Das famílias rurais do estado em 2008, cerca de 57,6\% tinham todos os seus membros com trabalho principal não-agrícola, 19,9\% eram pluriativas e outras 22,5\% eram essencialmente agrícolas. Proporções semelhantes já eram encontradas entre as famílias do rural paulista em $2004: 51,7 \%$ não-agrícolas, $21,3 \%$ pluriativas e $26,9 \%$ agrícolas. É de se notar a redução da participação de famílias agrícolas entre 2004 e 2008 e a ampliação de quase 6 p. p. na proporção das famílias não-agrícolas. Tabelas completas para o ano de 2004 e 2008 podem ser consultadas no Anexo. 
TABELA 1. DIMENSÃO DAS FAMÍLIAS RURAIS NO ESTADO DE SÃO PAULO EM 2008, SEGUNDO O CORTE GEOGRÁFICO E O TIPO DE FAMÍLIA

\begin{tabular}{c|c|c|c|c|c}
\hline & \multicolumn{2}{|c|}{ Indivíduos } & \multicolumn{2}{c|}{ Famílias } & $\begin{array}{c}\text { Dimensão } \\
\text { média da } \\
\text { família }\end{array}$ \\
\cline { 2 - 6 } & Número & $\%$ & Número & $\%$ & 3,3 \\
\hline Total do estado de SP & 2.337 .747 & 100 & 714.645 & 100 & \\
\hline Corte Geográfico & & & & & 3,5 \\
RMSP & 875.548 & 37.5 & 250.722 & 35,1 & 3,2 \\
SP s/ RMSP & 1.462 .199 & 62,5 & 463.923 & 64,9 & \\
\hline Tipo de Família & & & & & 2,9 \\
Família agrícola & 472.008 & 20,2 & 160.962 & 22,5 & 3,4 \\
Família não-agrícola & 1.412 .658 & 60,4 & 411.388 & 57,6 & 3,2 \\
Família pluriativa & 453.081 & 19,4 & 142.295 & 19,9 & \\
\hline
\end{tabular}

Fonte: elaborado a partir de microdados da PNAD (2008).

Constata-se, portanto, o peso relativamente menor da agricultura como atividade principal entre as famílias rurais em SP. Mesmo assim, 300 mil famílias em São Paulo em 2008 têm pelo menos um membro ocupado na agricultura. Na RMSP em 2008, 85,4\% das famílias rurais têm todos os seus membros ocupados em atividades não-agrícolas, o que representa o dobro da proporção das famílias rurais não-agrícolas no restante do estado, que foi de $42,5 \%$, devendo-se notar que cerca de $52 \%$ das famílias não-agrícolas do Estado se encontram na RMSP. Isso permite entender melhor a proximidade dos resultados encontrados para a RMSP e para as famílias não-agrícolas do estado $^{12}$.

A idade média entre as famílias rurais do estado de São Paulo em 2008 é de 30,6 anos, sendo que cerca de 1/3 dos indivíduos têm até 14 anos de idade ou 65 anos e mais, ou seja, para cada inativo, há duas pessoas potencialmente ativas (Tabela 2). A população rural da metrópole é relativamente mais jovem do que no restante do rural no estado e a proporção de pessoas em idade ativa nos dois cortes geográficos analisados é bastante semelhante. Nas famílias rurais agrícolas do estado a idade média é de 36,5 anos, quase nove anos a mais do que entre as famílias não-agrícolas, enquanto que a proporção de jovens é menor do que nos demais tipos de famílias. Reportando aos resultados de 2004 (Tabela 1A, do Anexo) são constatadas algumas mudanças dignas de nota nesse quinquênio : aumento de 1,5 ano na idade média dos residentes rurais do estado, sendo que o envelhecimento entre as famílias agrícolas foi de 5 anos, contra cerca de 1 ano para as não-agrícolas e pluriativas.

12 Tendo em vista o reduzido tamanho da amostra de famílias rurais agrícolas e pluriativas quando são consideradas isoladamente, não é possível realizar uma análise em separado desse grupo pelo corte geográfico escolhido (RMSP) e restante do estado de São Paulo. Contudo, como o número de famílias não-agrícolas é expressivo tanto na RMSP como no restante do estado, serão tecidos alguns comentários para esses subgrupos no intuito de oferecer algumas observações indicativas sobre seu perfil, que, naturalmente, devem ser tomadas com cautela. 
Esse resultado sugere duas tendências: envelhecimento geral da população rural que expressa a dinâmica populacional nesse momento no Brasil, simultaneamente a uma trajetória ocupacional em que a atividade agrícola deixa de ser atrativa para os mais jovens. Os resultados confirmam as constatações de Figueiredo e Branchi (2009), com base nas PNADs de 1992, 1999 e 2007, que sugerem haver uma tendência de envelhecimento das famílias rurais agrícolas no Brasil. Essa é uma tendência que tem sido observada também em outros países ${ }^{13}$.

TABELA 2. SÃO PAULO: DISTRIBUIÇÃO DOS INDIVÍDUOS DE ACORDO COM FAIXAS DE IDADE , CORTE GEOGRÁFICO E O TIPO DE FAMÍLIA (2008)

\begin{tabular}{l|c|c|c|c|c|c}
\hline & \multirow{2}{*}{$\begin{array}{c}\text { Indivíduos } \\
\text { (número) }\end{array}$} & \multirow{2}{*}{$\begin{array}{c}\text { Idade } \\
\text { (média) }\end{array}$} & \multicolumn{2}{|c|}{$\begin{array}{c}\text { Proporção por } \\
\text { faixa de idade (\%) }\end{array}$} & \multirow{2}{*}{ Razão(*) } \\
\cline { 5 - 6 } & & & $\begin{array}{c}\text { até } \\
\text { 14 anos }\end{array}$ & $\begin{array}{c}\mathbf{6 5} \text { anos } \\
\text { ou mais }\end{array}$ & $\begin{array}{c}\text { idade } \\
\text { ativa }\end{array}$ & \\
\hline Estado de SP & 2.337 .747 & 30,6 & 27,0 & 6,3 & 66,8 & 0,498 \\
\hline Corte Geográfico & & & & & & \\
RMSP & 875.548 & 27,7 & 29,9 & 3,5 & 66,6 & 0,501 \\
SP s/ RMSP & 1.462 .199 & 32,3 & 25,2 & 7,9 & 66,8 & 0,496 \\
\hline Tipo de Família & & & & & & \\
Família agrícola & 472.008 & 36,5 & 22,3 & 11,7 & 66,0 & 0,515 \\
Família não-agrícola & 1.412 .658 & 27,3 & 29,4 & 2,4 & 68,2 & 0,466 \\
Família pluriativa & 453.081 & 34,9 & 24,2 & 12,9 & 62,9 & 0,589 \\
\hline
\end{tabular}

Fonte: elaborado a partir de microdados da PNAD (2008). ${ }^{(*)}$ Razão de dependência.

A razão de dependência é um pouco mais baixa entre as famílias não-agrícolas, primordialmente devido à menor proporção de idosos. Para 2008, enquanto que nas famílias não-agrícolas há 2,15 adultos em idade ativa para cada indivíduo considerado inativo, nas famílias pluriativas e agrícolas esse número é de 1,70 e 1,94, respectivamente. Observou-se, ainda, uma queda da razão de dependência entre 2004 e 2008 em todos os cortes analisados, já que a diminuição da proporção de crianças e adolescentes suplantou o aumento da participação de idosos nesse período.

A Tabela 3 mostra que a escolaridade média nas famílias rurais é de 6,6 anos em 2008, considerando todos os indivíduos com 15 anos ou mais de idade, ou seja, em média a população rural não chega a completar o ensino fundamental. A proporção de analfabetos entre os indivíduos das famílias rurais com 15 anos ou mais em 2008 é de 9,5\% em todo o estado, chegando a 11,3\% fora da RMSP. Esses resultados mostram uma melhor situação da educação formal da população do estado com relação à 2004, quando foram registrados 
escolaridade média de 5,8 anos e 10,3\% de analfabetos. Observa-se pelos resultados de 2008 que o analfabetismo está em torno de 18\% entre as famílias rurais agrícolas e 15\% entre as pluriativas, muito acima do registrado para as famílias não-agrícolas, que é de 4,4\%. No entanto, os jovens entre 15 a 25 anos, de todos os tipos de famílias rurais, estão estudando mais do que as gerações anteriores, o que deve contribuir para elevar o baixo nível de escolaridade presente atualmente. Os jovens de famílias pluriativas apresentam grau de escolaridade próximo ao dos pertencentes a famílias não-agrícolas, sugerindo que teriam condições semelhantes, quanto à escolaridade, para disputar posições no mercado de trabalho. Finalmente, é preciso notar que em média os jovens de famílias agrícolas estudam menos, significando que partem de um patamar de escolaridade mais baixo que os demais quando da inserção no mercado de trabalho. Políticas específicas para a qualificação do jovem que se dedica à agricultura devem contribuir para elevar sua capacidade de absorver novas tecnologias, desempenhar com maior facilidade suas atividades diante das mudanças tecnológicas em curso na agricultura, contribuir para fixá-lo à terra e para o desenvolvimento agrário.

TABELA 3. SÃO PAULO: ESCOLARIDADE MÉDIA POR FAIXAS DE IDADE E TAXA DE ANALFABETISMO PARA OS INDIVÍDUOS DE 15 ANOS OU MAIS, PERTENCENTES A FAMÍLIAS RURAIS, SEGUNDO O CORTE GEOGRÁFICO E O TIPO DE FAMÍLIA RURAL (2008)

\begin{tabular}{|c|c|c|c|c|c|}
\hline & \multicolumn{4}{|c|}{ Escolaridade Média por faixas de idade } & \multirow{2}{*}{$\begin{array}{c}\text { Taxa de } \\
\text { Analfabetismo } \\
\text { (\%) }\end{array}$} \\
\hline & $\begin{array}{c}15 \text { a } 25 \\
\text { anos }\end{array}$ & $\begin{array}{c}26 \text { a } 64 \\
\text { anos }\end{array}$ & $\begin{array}{c}65 \text { anos } \\
\text { e mais }\end{array}$ & $\begin{array}{c}\text { Total } \\
\geq 15 \text { anos }\end{array}$ & \\
\hline Estado de SP & 8,9 & 6,3 & 2,2 & 6,6 & 9,5 \\
\hline \multicolumn{6}{|l|}{ Corte Geográfico } \\
\hline RMSP & 9,2 & 7,0 & 1,9 & 7,4 & 6,3 \\
\hline SP sem RMSP & 8,8 & 5,9 & 2,3 & 6,2 & 11,3 \\
\hline \multicolumn{6}{|l|}{ Tipo de Família } \\
\hline Família agrícola & 7,6 & 4,5 & 2,3 & 4,7 & 18,1 \\
\hline Família não-agrícola & 9,3 & 7,1 & 2,7 & 7,6 & 4,4 \\
\hline Família pluriativa & 9,0 & 5,4 & 1,9 & 5,7 & 14,9 \\
\hline
\end{tabular}

Fonte: elaborado a partir de microdados da PNAD (2008).

Pela Tabela 4 pode-se verificar que entre os indivíduos com 10 anos ou mais, pertencentes a famílias rurais de São Paulo, 57,3\% estavam ocupados em 2008. Seria de se esperar maior grau de ocupação na RMSP do que no restante do estado, pelas oportunidades que a metrópole pode oferecer. No entanto, na RMSP apenas 53,6\% dessa população encontra-se ocupada, o que poderia ser explicado, em parte, pela maior presença de jovens na escola ou então pela maior proporção de aposentados e pensionistas e famílias que dependem de outras fontes de renda que não a do trabalho. Observando-se os cortes familiares, nota-se que a proporção de ocupados entre as famílias pluriativas é 
de apenas $46 \%$, bem abaixo dos valores observados para as famílias agrícolas e não-agrícolas. Esse quadro é semelhante ao traçado em 2004 (Tabela 1A, do Anexo) quando a população rural ocupada era 55,2\%.

TABELA 4. SÃO PAULO: POPULAÇÃO RURAL COM MAIS DE 10 ANOS DE IDADE; NÚMERO E PROPORÇÃO DE OCUPADOS E NÚMERO E PROPORÇÃO DE EMPREGADOS COM CARTEIRA ASSINADA NO TRABALHO PRINCIPAL, SEGUNDO O CORTE GEOGRÁFICO E O TIPO DE FAMÍLIA RURAL (2008)

\begin{tabular}{|l|c|c|c|c|}
\hline & $\begin{array}{c}\text { Número de } \\
\text { ocupados }\end{array}$ & $\begin{array}{c}\text { \% } \\
\text { ocupados }\end{array}$ & $\begin{array}{c}\text { Número de } \\
\text { empregados }\end{array}$ & $\begin{array}{c}\text { \% empregados c/ } \\
\text { carteira assinada }\end{array}$ \\
\hline Estado de SP & 1.112 .981 & 57,3 & 808.075 & 71,2 \\
\hline Corte Geográfico & & & & \\
\hline RMSP & 384.962 & 53,6 & 316.854 & 73,2 \\
\hline SP sem RMSP & 728.019 & 59,4 & 491.221 & 69,9 \\
\hline Tipo de Família & & & & \\
\hline Família agrícola & 247.443 & 62,1 & 118.844 & 65,2 \\
\hline Família não-agrícola & 684.346 & 59,4 & 572.171 & 75,1 \\
\hline Família pluriativa & 181.192 & 46,0 & 117.060 & 58,4 \\
\hline
\end{tabular}

Fonte: elaborado a partir de microdados da PNAD (2008).

Com relação à formalização no trabalho, nota-se que no rural paulista em 2008 apenas $71,2 \%$ dos ocupados na categoria de empregados, tinham carteira assinada, sendo $73,2 \%$ na RMSP. Entre os tipos de família rural as pluriativas apresentam menor formalização, com apenas 58,4\% dos empregados com carteira assinada, seguindo-se agrícolas, com $65,2 \%$, e não-agrícolas, com 75,1\% dos empregados no mercado formal. Esses resultados sugerem que a participação em atividades não-agrícolas contribui para uma maior formalização do trabalho, porém, isso não vale para as famílias pluriativas, provavelmente pelas condições precárias de emprego que usufruem.

Pela comparação dos resultados de 2004 nota-se um aumento de quase 10 p. p. na proporção de empregados rurais com carteira no estado de São Paulo. Registre-se ainda que esse progresso não ocorreu de forma uniforme nos grupos estudados, sendo mais intenso entre os empregados do rural metropolitano e pertencentes a famílias não-agrícolas. Já nas famílias pluriativas, a proporção de empregados formais caiu de 2 p.p., novamente sugerindo que este grupo é o que enfrenta a maior precariedade no trabalho.

A partir da amostra de 2,31 milhões de pessoas com domicílio rural em 2008 para as quais se dispõe de dados completos sobre rendimentos, foram calculadas as principais medidas da distribuição dos rendimentos das famílias rurais segundo cortes regionais e tipos de famílias, apresentados nas tabelas 5 e 6 . 
A renda média das famílias rurais de São Paulo em 2008 é de $\mathrm{R} \$ 1.391,23$, havendo pouca diferença entre o rendimento familiar médio na RMSP e nas demais áreas rurais do estado. No entanto, a renda familiar per capita é cerca de 10\% menor na RMSP, resultado da dimensão média das famílias que é de 3,49 membros no rural da RMSP, e 3,15 nas demais áreas rurais do estado (Tabela 5). Pela Tabela 6, nota-se que as famílias rurais não-agrícolas possuem rendimentos familiar total e per capita mais altos, 10,1\% a mais com relação às famílias rurais e 13,6\% a mais com relação às famílias pluriativas.

TABELA 5. SÃO PAULO: RENDA FAMILIAR E INDICADORES DE POBREZA E DESIGUALDADE DA DISTRIBUIÇÃO DE RENDA, SEGUNDO O CORTE GEOGRÁFICO E O TIPO DE FAMÍliA RURAL ( $\left.\begin{array}{llllll}2 & \text { o } & 0 & 8\end{array}\right)$

\begin{tabular}{l|c|c|c}
\hline \multicolumn{1}{c|}{ Indicadores da distribuição de renda } & $\begin{array}{c}\text { Estado de } \\
\text { SP }\end{array}$ & RMSP & $\begin{array}{c}\text { SP s/ } \\
\text { RMSP }\end{array}$ \\
\hline $\begin{array}{l}\text { Renda familiar média } \\
\text { (R\$, preços de set. de 2008, segundo o INPC) }\end{array}$ & 1391,23 & $1.385,46$ & 1394,69 \\
\hline $\begin{array}{l}\text { Renda familiar per capita - RFPC } \\
\text { (R\$, preços de set. de 2008, segundo o INPC) }\end{array}$ & 407,72 & 369,62 & 430,58 \\
\hline $\begin{array}{l}\text { Proporção de pobres - \% } \\
\text { (RFPC < 1/2 S.M.) }\end{array}$ & 30,0 & 30,0 & 30,0 \\
\hline $\begin{array}{l}\text { Proporção de indigentes - \% } \\
\text { (RFPC 1/4 S.M.) }\end{array}$ & 10,3 & 11,5 & 9,6 \\
\hline $\begin{array}{l}\text { FGT } \\
\text { (linha pobreza: RFPC < 1/2 S.M.) }\end{array}$ & 0,369 & 0,408 & 0,345 \\
\hline $\begin{array}{l}I \\
\text { (linha pobreza: RFPC < 1/2 S.M.) }\end{array}$ & 0,280 & 0,286 & 0,227 \\
\hline Índice de Gini & 0,4172 & 0,3723 & 0,4386 \\
\hline
\end{tabular}

Fonte: elaborado a partir de microdados da PNAD (2008). 
TABELA 6. SÃO PAULO: RENDA FAMILIAR E INDICADORES DE POBREZA E DESIGUALDADE DA DISTRIBUIÇÃO DE RENDA, SEGUNDO O CORTE GEOGRÁFICO E O TIPO DE FAMÍLIA RURAL (2008)

\begin{tabular}{l|c|c|c}
\hline Indicadores da distribuição de renda & agrícola & não-agrícola & pluriativa \\
\hline $\begin{array}{l}\text { Renda familiar média } \\
\text { (R\$, preços de set. de 2008, segundo o INPC) }\end{array}$ & 1145,19 & 1506,11 & 1288,72 \\
\hline $\begin{array}{l}\text { Renda familiar per capita - RFPC } \\
\text { (R\$, preços de set. de 2008, segundo o INPC) }\end{array}$ & 384,35 & 427,75 & 369,65 \\
\hline $\begin{array}{l}\text { Proporção de pobres } \\
\text { (RFPC < 1/2 S.M.) - \% }\end{array}$ & 34,0 & 26,9 & 35,4 \\
\hline $\begin{array}{l}\text { Proporção de indigentes - \% } \\
\text { (RFPC < 1/4 S.M.) }\end{array}$ & 8,6 & 9,1 & 16,1 \\
\hline $\begin{array}{l}F G T \\
\text { (linha pobreza: RFPC < 1/2 S.M.) }\end{array}$ & 0,365 & 0,259 & 0,712 \\
\hline $\begin{array}{l}I \\
\text { (linha pobreza: RFPC < 1/2 S.M.) }\end{array}$ & 0,304 & 0,229 & 0,416 \\
\hline Índice de Gini & 0,4308 & 0,4130 & 0,4110 \\
\hline
\end{tabular}

Fonte: elaborado a partir de microdados da PNAD (2008).

Pela comparação dos resultados de 2008 e 2004, constata-se um aumento real de 22,3\% na renda familiar per capita das famílias rurais do estado de São Paulo, podendo-se creditar esse aumento a pelo menos três fatores: aumento real da renda; aumento do número de ocupados; e diminuição do tamanho da família. Os incrementos foram maiores para as famílias agrícolas e pluriativas e aquelas residentes na metrópole.

A proporção de pobres em 2008 é de cerca de 30\%, tanto no rural da RMSP como nas demais áreas rurais do estado, resultado próximo a 30,5\%, obtido em 2004, bem como aos valores encontrados em outros estudos com dados para São Paulo em anos anteriores ${ }^{14}$, indicando que a extensão da pobreza rural em São Paulo pouco se alterou nos últimos anos. Pelo índice FGT verifica-se que a pobreza é mais severa na RMSP, tendo em vista que esse índice sintetiza três dimensões da pobreza: a proporção de pobres, a razão de insuficiência de renda e a distribuição da renda entre os pobres. Segundo os resultados por tipo de família, nas famílias não-agrícolas a proporção de pobres é menor e o índice FGT também indica que estão em melhor situação. As famílias pluriativas estão em franca desvantagem porque, além do rendimento familiar per capita menor, também apresentam maior proporção de pobres e uma proporção de indigentes quase o dobro dos demais grupos. O índice FGT para as famílias pluriativas confirma a severidade da pobreza entre os pluriativos: os pobres nesse grupo são mais pobres que nos demais.

14 Kageyama (2008), com dados da PNAD 2005, apresenta um valor de 30,44\% para a proporção de pobres em São Paulo, considerando a renda domiciliar per capita. 
Conquanto a proporção média de pobres no estado pouco tenha se alterado entre 2004 e 2009, foram registradas algumas mudanças dignas de nota: queda da proporção de pobres e indigentes na RMSP, de 3,6 p.p. e 5,5 p.p., respectivamente; disparidade nas variações, sendo que para as famílias agrícolas a queda na proporção de pobres foi de quase 9 p.p., e para as não-agrícolas e pluriativas houve um incremento de cerca de 3 p.p..

Resumindo, as famílias pluriativas de um modo geral estão em pior situação quanto à renda e pobreza, sendo que a severidade da pobreza nesse grupo é maior e piorou no tempo. Dessa forma, dentro dos limites da presente pesquisa, a pluriatividade não está representando um caminho para aliviar a pobreza das famílias rurais do estado de São Paulo. Resultado semelhante foi encontrado em estudo para o Brasil em 1992, 1999 e 2007 por Figueiredo e Branchi (2009). Como observa Kageyama (2008:197), os empregos rurais não-agrícolas são geralmente de baixa qualidade na maioria das regiões. Seguindo a tendência de queda na desigualdade de renda observada no Brasil em geral, no meio rural paulista a desigualdade medida pelo índice de Gini para o rendimento familiar per capita em 2008 ela é menor na RMSP, com relação às demais regiões, e entre as famílias não-agrícolas e pluriativas. Seria de se esperar que a desigualdade fosse maior entre as famílias nãoagrícolas e pluriativas, tendo em vista que uma maior diversidade de ocupações também cria oportunidades para uma diferenciação de rendimentos no rural. Esse resultado não esperado deveria ser objeto de investigação futura.

A Tabela 7 resume a participação das diversas fontes de rendimento no rendimento familiar per capita médio. Com base nas informações publicadas pela PNAD são consideradas as seguintes fontes: rendimento do trabalho (todos), renda de aposentadorias, pensões e abono de permanência, aluguéis, doações de não-residentes do domicílio, e um item que inclui, entre outros, juros, dividendos e benefícios advindos dos programas sociais do governo ${ }^{15}$. A Figura 1 ilustra a participação percentual de cada fonte no rendimento familiar per capita médio.

15 Infelizmente a PNAD não disponibiliza cada uma dessas fontes em separado, o que limita a avaliação da participação de programas sociais do governo na renda das famílias a partir dessa fonte de dados. 
FIGUEIREDO, N. M. S.; BRANCHI, B. A.; KAGEYAMA, A. A. Trabalhadores e famílias rurais...

TABELA 7. SÃO PAULO: RENDIMENTO FAMILIAR PER CAPITA POR FONTE DE RENDA DAS FAMÍLIAS RURAIS, SEGUNDO CORTES REGIONAIS E TIPO DE FAMÍLIA (2008)

\begin{tabular}{|c|c|c|c|c|c|c|}
\hline \multirow{2}{*}{ Fontes de renda } & \multirow{2}{*}{$\begin{array}{l}\text { Estado } \\
\text { de SP }\end{array}$} & \multicolumn{2}{|c|}{ Corte regional } & \multicolumn{3}{|c|}{ Tipo de Família } \\
\hline & & RMSP & $\begin{array}{l}\text { SP s/ } \\
\text { RMSP }\end{array}$ & agrícola & $\begin{array}{c}\text { não } \\
\text { agrícola }\end{array}$ & pluriativa \\
\hline Todos os trabalhos & 326,47 & 322,43 & 328,90 & 253,38 & 381,17 & 232,10 \\
\hline $\begin{array}{l}\text { Aposentadoria, } \\
\text { pensão, abono }\end{array}$ & 68,59 & 39,46 & 86,07 & 111,15 & 37,34 & 121,69 \\
\hline Aluguel & 4,05 & 1,88 & 5,34 & 5,91 & 2,73 & 6,20 \\
\hline Doação & 0,11 & 0,00 & 0,18 & 0,45 & 0,03 & 0,00 \\
\hline $\begin{array}{l}\text { Juros, dividendos, } \\
\text { programas,etc. }\end{array}$ & 8,50 & 5,84 & 10,09 & 13,45 & 6,48 & 9,65 \\
\hline $\begin{array}{l}\text { Renda familiar } \\
\text { per capita }\end{array}$ & 407,72 & 369,62 & 430,58 & 384,35 & 427,75 & 369,65 \\
\hline
\end{tabular}

Fonte: elaborado a partir de microdados da PNAD (2008).

Nota-se que a renda do trabalho corresponde a cerca de $80 \%$ do total da renda familiar entre as famílias rurais de São Paulo, chegando a mais de $87 \%$ no rural da RMSP. Entre as famílias não agrícolas, essa proporção é de 89,1\%, nível substancialmente mais elevado do que nos demais tipos de famílias, $65,9 \%$ entre as famílias agrícolas e $62,8 \%$ entre as pluriativas. O peso das aposentadorias e pensões é maior no rural não metropolitano de São Paulo, resultado esperado tendo em vista a maior proporção de idosos. O peso das aposentadorias e pensões ${ }^{16}$ é relevante entre as famílias pluriativas (cerca de um terço do rendimento total) e famílias agrícolas (cerca de $29 \%$ do total), enquanto que para as famílias não-agrícolas é de apenas $8,7 \%$. Os aluguéis têm pequena participação na composição da renda familiar per capita, de cerca de $1,2 \%$ no rural não metropolitano e $0,5 \%$ na RMSP. Seu peso é de $1,7 \%, 1,5 \%$ e $0,6 \%$ na renda das famílias pluriativas, agrícolas e não-agrícolas, respectivamente. $\mathrm{O}$ último item, que inclui entre outros juros, dividendos e recebimentos de benefícios advindos de programas sociais do governo, tem uma participação média de 2,1\% no rendimento familiar per capita das famílias rurais de São Paulo, sendo mais importante na composição da renda no rural não metropolitano e famílias agrícolas e pluriativas, justamente as categorias que apresentam menor renda e maior nível de pobreza, sugerindo que nesse caso os rendimentos dessa fonte sejam constituídos predominantemente por transferências através de programas de combate à pobreza.

16 Essa categoria é formada basicamente por rendimentos de aposentadorias e pensões, tendo em vista a participação inexpressiva de abono de permanência no total. 
FIGURA 1. SÃO PAULO: PARTICIPAÇÃO PERCENTUAL DAS FONTES DE RENDIMENTO DAS FAMÍLIAS RURAIS, SEGUNDO O CORTE METROPOLITANO/NÃO-METROPOLITANO E POR TIPO DE FAMÍLIA (2008)

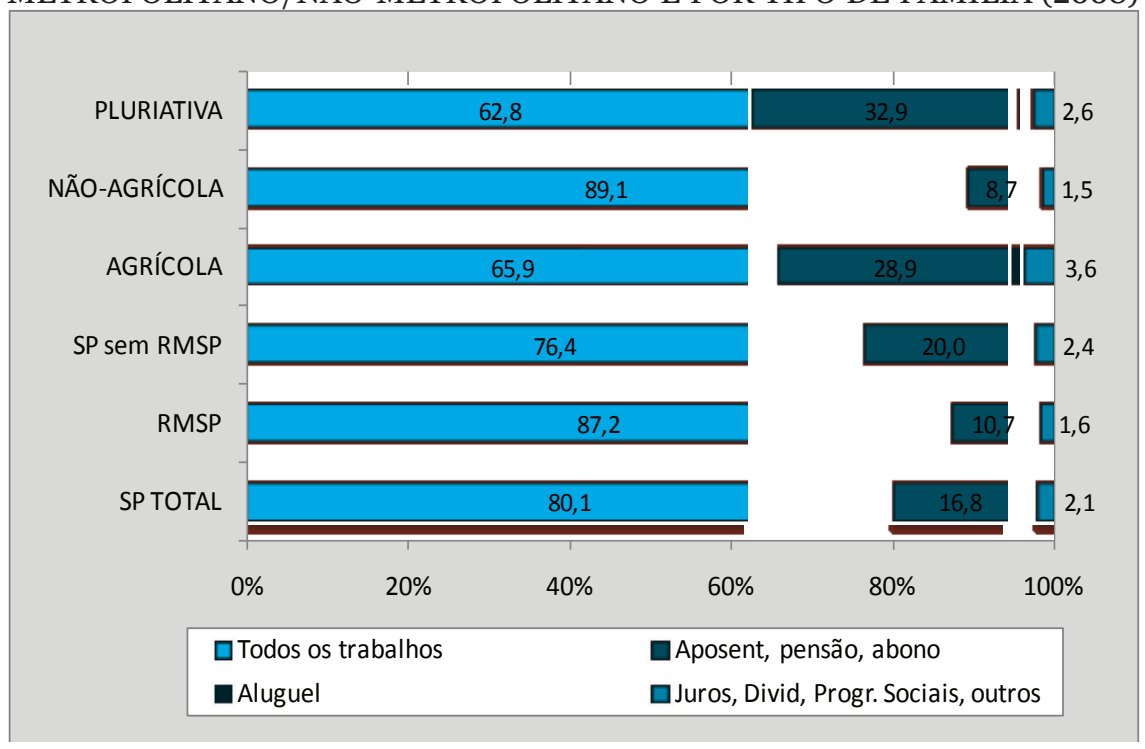

Fonte: elaborado a partir de microdados da PNAD (2008).

As principais mudanças ocorridas na composição da renda, com relação ao ano de 2004, se notam para as famílias pluriativas e para aquelas residentes na área rural metropolitana. Nesses dois grupos caiu o peso das aposentadorias e aumentou a participação do rendimento do trabalho, resultado decorrente da maior ocupação entre esses grupos, como apontado anteriormente.

Alguns indicadores das condições de vida das famílias rurais são apresentados na Tabela 8. O índice de nível de vida rural (INVR), dado pela média aritmética dos seis indicadores da tabela, expressa, de forma sintética, as condições de vida dos indivíduos das famílias rurais de São Paulo. Primeiramente, é possível identificar que o acesso aos vários bens e serviços listados na tabela é bastante homogêneo, tanto nos cortes regionais como para as diferentes categorias de famílias, exceto para o escoamento sanitário, que de certa forma é o determinante principal das diferenças dos índices entre os tipos de famílias e regiões encontrados nesta pesquisa. Dessa forma, o índice de qualidade de vida menor para os indivíduos das famílias rurais residentes fora da RMSP, com relação às da RMSP, se deve à proporção extremamente baixa de acesso a esgoto sanitário para as famílias rurais fora da metrópole. Nota-se também que no rural não metropolitano o único item em que as famílias rurais encontram-se em clara vantagem é o acesso à água canalizada. Dessa forma, apesar do rendimento familiar per capita menor e da maior severidade da pobreza, as famílias da RMSP desfrutam de melhor qualidade de vida. 
TABELA 8. SÃO PAULO: ÍNDICE DE NÍVEL DE VIDA RURAL (INVR) E SUAS COMPONENTES (\% DE FAMÍLIAS QUE POSSUEM O BEM), SEGUNDO O TIPO DE FAMÍLIA RURAL E REGIÃO (2008)

\begin{tabular}{c|c|c|c|c|c|c|c}
\hline & $\begin{array}{c}\text { Água } \\
\text { canalizada }\end{array}$ & Banheiro & Esgoto & $\begin{array}{c}\text { Luz } \\
\text { elétrica }\end{array}$ & Geladeira & Telefone & INVR \\
\hline Estado de SP & 0,915 & 0,995 & 0,635 & 0,992 & 0,958 & 0,849 & 0,891 \\
\hline RMSP & 0,894 & 0,994 & 0,882 & 0,994 & 0,989 & 0,886 & 0,940 \\
\hline SP s/ RMSP & 0,927 & 0,995 & 0,488 & 0,990 & 0,940 & 0,826 & 0,861 \\
\hline Tipo de Família & & & & & & & \\
\hline Agrícola & 0,946 & 0,992 & 0,254 & 0,996 & 0,926 & 0,714 & 0,805 \\
\hline Não-agrícola & 0,908 & 0,995 & 0,802 & 0,997 & 0,980 & 0,899 & 0,930 \\
\hline Pluriativa & 0,904 & 0,996 & 0,510 & 0,972 & 0,923 & 0,833 & 0,856 \\
\hline
\end{tabular}

Fonte: elaborado a partir de microdados da PNAD (2008).

Entre as categorias de famílias rurais, as não-agrícolas gozam de melhor qualidade de vida do que as demais, apresentando um valor do INVR 8\% maior com relação às famílias pluriativas, e $16 \%$ maior do que as famílias agrícolas. Novamente o item acesso a escoamento sanitário foi determinante desse resultado, e o acesso a telefone também contribuiu para deprimir o valor do índice para as famílias rurais agrícolas. Comparando com os indicadores de renda, as famílias rurais pluriativas e agrícolas apresentam maior proporção de pobres, maior severidade da pobreza, menor renda familiar per capita, e índice de qualidade de vida inferior comparativamente às famílias não-agrícolas.

Comparando esses resultados com os dados de 2004 verifica-se o notável aumento de $46 \%$ na proporção de indivíduos com telefone fixo ou celular, o que foi facilitado no meio rural pela difusão da telefonia celular. Considerando apenas os indivíduos de famílias agrícolas o aumento foi de 127\%. O aumento da proporção de pessoas em domicílios com esgotamento sanitário também é digno de nota, particularmente para os residentes nas áreas rurais não metropolitanas. Em média, o índice de qualidade de vida rural experimentou um incremento de 7,1\%, sendo que no grupo das famílias agrícolas e no rural não-metropolitano foram observados os maiores avanços, justamente os grupos que se encontravam em piores condições em 2004. Esse fato sugere uma tendência de equalização da qualidade de vida rural entre as famílias rurais no estado de São Paulo. 


\section{Características dos chefes de famílias rurais}

Selecionadas as pessoas responsáveis pela família, foram obtidas 714.637 observações em 2008 para chefes, dos quais 565.734 estavam ocupados na semana de referência (incluindo afastados, autoprodução e autoconstrução). Para estes, buscou-se investigar se há diferenças de perfil socioeconômico e demográfico, por tipo de família e por corte geográfico. Pela Tabela 9, os chefes das famílias rurais de São Paulo são na maioria do sexo masculino (83,5\%), com idade média próxima a 43,3 anos, e escolaridade média de 6,3 anos, portanto, sem educação fundamental completa. A idade média dos chefes das famílias rurais da RMSP e das não-agrícolas é menor que nos demais cortes, confirmando os resultados anteriores que apontaram famílias não-agrícolas ou localizadas na RMSP em média mais jovens. A escolaridade média também é relativamente mais alta entre os chefes desses dois grupos de famílias.

Para esses dois cortes, a proporção de chefes do sexo feminino é maior, chegando a quase $1 / 4$ do total de chefes, enquanto mais de $90 \%$ das famílias agrícolas e pluriativas são chefiadas por homens. Interessante notar também que os chefes da RMSP e das famílias não-agrícolas, onde a proporção de chefes mulheres é maior, a proporção de ocupados em serviços domésticos também é maior - em torno de $15 \%$ dos ocupados. A título de curiosidade, limitando a análise às chefes do sexo feminino, verificou-se que $38,8 \%$ são chefes mulheres ocupadas em serviços domésticos.

Os principais setores de atividade são agricultura (35,6\%), indústria de transformação (11\%), construção (10,2\%), serviços domésticos $(9,4 \%)$, seguindo-se comércio e reparação, transporte e armazenagem e alojamento e alimentação. Atividades na indústria, na construção, comércio, transporte e serviços domésticos são mais comuns entre os chefes da RMSP e entre as famílias não-agrícolas. No rural não metropolitano há uma prevalência de chefes ocupados na agricultura, 51,7\%, contra 4,6\% na RMSP como era de esperar dada a grande presença de famílias não agrícolas no rural metropolitano. Entre as famílias pluriativas, $86 \%$ dos chefes têm ocupação principal na agricultura, o que sugere que nestas, enquanto o chefe se dedica à agricultura, outros membros buscam oportunidades de trabalho fora da agricultura.

Com relação à posição na ocupação a proporção de chefes na categoria de empregados é mais alta na RMSP e nas famílias não-agrícolas, girando em torno de $80 \%$. Entre as chefes mulheres essa proporção é de $91,8 \%$. Para chefes de famílias pluriativas e agrícolas a proporção de conta-própria é maior, bem como a proporção de chefes envolvidos em atividades de autoconsumo, autoconstrução e não-remunerados, sugerindo, também com relação a esse indicador, a precariedade da inserção dessas famílias no mercado de trabalho. 
Entre os chefes ocupados como empregado, mais de 2/3 tinham carteira assinada, sendo que na RMSP e entre as famílias não-agrícolas essa proporção ultrapassa 78\%. Nota-se menor formalização entre os chefes ocupados na agricultura, onde 34\% são trabalhadores informais. A soma da proporção dos chefes com trabalho informal, e dos envolvidos em atividades de autoconsumo e autoconstrução resulta em 48,4\% dos chefes de famílias agrícolas e 44,1\% dos chefes de famílias pluriativas em situação bastante precária quanto à ocupação. Os resultados por gênero dos chefes mostram que 85,1\% dos chefes homens têm carteira assinada contra 60,1\% das mulheres e que 73,0\% das mulheres chefes de famílias não-agrícolas ocupadas em serviços domésticos têm carteira assinada.

Comparando os chefes das famílias não-agrícolas nos dois rurais (duas últimas colunas da Tabela 9, em anexo) constata-se que os perfis são muitos parecidos. A única diferença é que o rural da RMSP é tipicamente não agrícola: 94,87\% dos chefes ocupados da RMSP desenvolviam atividades não-agrícolas, contra 46,23\% no rural não metropolitano do Estado. Ou, diferentemente, 51,42\% dos chefes de famílias não-agrícolas do estado se encontram na RMSP.

Os resultados para 2004 (Tabela 2A, no Anexo) mostram que a proporção de chefes ocupados aumentou 12\% entre 2004 e 2008, acompanhando a tendência observada para a economia como um todo nesse quinquênio. Detectou-se também um aumento da idade média, de 3\% no rural metropolitano e entre os chefes de famílias agrícolas.

Os principais setores de atividade dos chefes rurais em 2004 são agricultura, indústria de transformação, construção e serviços domésticos $(9,4 \%)$, porém a proporção de ocupados em atividades agrícolas e nos serviços domésticos era maior nesse ano, comparativamente a 2008. Por outro lado, a proporção de chefes rurais ocupados na indústria aumentou em cerca de 14\%, sugerindo que a evolução das condições do mercado de trabalho nesse período afastou os chefes de atividades mais precárias, justamente aquelas que remuneram pior e em que existe maior informalidade, incorporando-os a um mercado de trabalho mais formalizado e de maiores salários.

Com relação à posição na ocupação, a comparação dos números de 2004 e 2008 mostram que na média houve uma queda da proporção dos chefes ocupados por conta-própria. No rural não-metropolitano e entre as famílias pluriativas verificou-se um aumento notável do número e da proporção daqueles envolvidos em atividades de autoconsumo e autoconstrução provavelmente como saídas para o aumento do desemprego rural já apontado por outros estudos. Novamente é possível constatar a precariedade da pluriatividade no rural paulista. No rural metropolitano houve queda da proporção de chefes em atividades de autoconsumo, sendo que a proporção de chefes empregados com carteira assinada experimentou um notável aumento de $32 \%$. 
TABELA 10. SÃO PAULO: CHEFES NÃO OCUPADOS DAS FAMÍLIAS RURAIS, SEGUNDO IDADE E PRINCIPAIS FONTES DE RENDIMENTOS POR CORTE GEOGRÁFICO E TIPO DE FAMÍLIA (2008)

\begin{tabular}{l|c|c|c|c|c|c}
\hline & \multirow{2}{*}{$\begin{array}{c}\text { Estado } \\
\text { de SP }\end{array}$} & \multicolumn{2}{|c|}{ Corte Geográfico } & \multicolumn{3}{|c}{ Tipo de Família } \\
\cline { 3 - 7 } & RMSP & $\begin{array}{c}\text { SP s/ } \\
\text { RMSP }\end{array}$ & agrícola & não-agrícola & pluriativa \\
\hline $\begin{array}{l}\text { N. o de chefes não } \\
\text { ocupados }\end{array}$ & 148.903 & 58.238 & 90.665 & 18.590 & 56.230 & 74.083 \\
\hline $\begin{array}{l}\text { \% de chefe } \\
\text { não-ocupados }\end{array}$ & 20,8 & 23,2 & 19,5 & 11,5 & 13,7 & 52,1 \\
\hline $\begin{array}{l}\text { \% de chefe desocupado } \\
\text { Idade média }\end{array}$ & 55,6 & 49,7 & 59,4 & 66,5 & 48,0 & 58,7 \\
\hline $\begin{array}{l}\text { \% chefes } \\
\text { c/ aposentadoria }\end{array}$ & 48,3 & 37,3 & 55,3 & 71,6 & 23,2 & 61,4 \\
\hline $\begin{array}{l}\text { \% chefes } \\
\text { c/ pensão }\end{array}$ & 15,7 & 8,5 & 20,4 & 33,1 & 16,0 & 11,1 \\
\hline $\begin{array}{l}\text { \% chefes } \\
\text { c/ renda de aluguéis }\end{array}$ & 4,9 & 3,4 & 5,8 & 4,7 & 5,1 & 4,8 \\
\hline $\begin{array}{l}\text { \% chefes c/ rendas } \\
\text { de juros, dividendos, } \\
\text { programas sociais, etc. }\end{array}$ & 11,7 & 10,2 & 12,6 & 14,2 & 11,5 & 11,1 \\
\hline
\end{tabular}

Fonte: elaborado a partir de microdados da PNAD (2008).

Tendo em vista a alta proporção de chefes não-ocupados nas famílias rurais de São Paulo (20,1\% do total) são investigadas algumas características que possam indicar se isso se deve à falta de oportunidades de trabalho ou não. Pela Tabela 10, verifica-se que os chefes não ocupados são em média 12,3 anos mais idosos do que os chefes ocupados. Considerando os chefes residentes na RMSP, eles são em média 10 anos mais jovens do que os residentes no restante do Estado, o que suscita alguma preocupação com relação aos motivos pelos quais esses chefes não estão ocupados. Busca-se então investigar quais as fontes de renda do chefe, segundo os cortes analisados nesta pesquisa. Segundo a mesma tabela, $48,3 \%$ dos chefes não ocupados declararam receber aposentadoria e $15 \%$ eram pensionistas pelo sistema público ${ }^{17}$; cerca de $5 \%$ recebiam aluguéis e mais de um décimo tinham algum rendimento incluído no item juros, dividendos, benefícios de programas sociais do governo e outras fontes ${ }^{18}$. Cerca de $14 \%$ dos chefes não ocupados de famílias agrícolas declararam receber rendimento desta última fonte. Em 2004, a proporção de chefes não ocupados é pouco mais que 19\%, valor próximo ao de 2008. Da constatação anterior sobre o crescimento de $15 \%$ da ocupação, há indicativos de que essa expansão do número de ocupados se deve à maior participação dos membros da família no mercado de trabalho (Tabela 3A, no Anexo)

17 Note-se que pela legislação brasileira a pessoa pode acumular mais de um benefício.

18 Tendo em vista os baixos níveis de rendimento médio das famílias rurais, é de se supor que esse item inclua, predominantemente, transferências do governo através de programas sociais como o "Bolsa-Família". 
A análise por corte geográfico indica que na RMSP uma menor proporção de chefes não ocupados tem acesso às fontes de renda alternativas ao trabalho, conforme a Tabela 10, o que sugere uma falta de oportunidades de trabalho para os chefes rurais da RMSP. No caso dos chefes desocupados das famílias rurais não metropolitanas e das famílias agrícolas e pluriativas, é evidente a maior proporção de aposentados e pensionistas que nos demais tipos de famílias.

\section{Conclusões}

A constatação de que $37 \%$ da população rural do estado de São Paulo reside na sua principal Região Metropolitana em 2008 suscitou este estudo. Apesar de que sabidamente a classificação administrativa rural-urbano adotada pelo IBGE apresenta problemas frente às conceituações sociológicas dessas categorias, julgou-se pertinente explorar, a partir dos dados da $\mathrm{PNAD}$, as principais características desses residentes rurais metropolitanos. Paralelamente, com intuito de comparações, foram pesquisadas as famílias rurais do estado segundo sua condição setorial de atividade (agrícola, não-agrícola e pluriativa).

Quanto ao primeiro corte (rural metropolitano versus rural não-metropolitano ${ }^{19}$ ), a principal conclusão é que as famílias rurais da RMSP em 2008 são eminentemente não-agrícolas, isto é, possuem todos os seus membros ocupados em atividades não-agrícolas. As famílias não-agrícolas correspondem a 85\% das famílias rurais metropolitanas. Menos de $5 \%$ dos chefes de famílias rurais na RMSP estão ocupados em atividades agrícolas, contra 52\% em média nas outras áreas do estado.

Esse fato praticamente condiciona as características das famílias rurais metropolitanas, em termos de estrutura etária, escolaridade, formalização do emprego e alguns equipamentos domiciliares. Assim como o total das famílias rurais não-agrícolas do estado, os rurais metropolitanos são em média mais jovens, possuem maior escolaridade, mais empregos formais e maior acesso a itens como água encanada e menor acesso a escoamento sanitário em 2008. As famílias rurais do restante do estado são em média mais velhas, com menor escolaridade e com menor acesso a empregos formais.

No entanto, as famílias rurais da região metropolitana encontram-se em piores condições do que as famílias rurais não-agrícolas em geral e do que as famílias rurais não-metropolitanas no que se refere a rendimento e pobreza, ou seja, apresentam em média menor rendimento e pobreza mais severa (em termos do índice FGT). Esse resultado contrasta com o encontrado por estudos de metrópoles de países desenvolvidos. Por exemplo, Plessis et al.

19 Lembre-se que São Paulo possui ainda mais duas regiões metropolitanas (Campinas e Santos), cujas áreas rurais ficaram junto com o "rural não-metropolitano", que corresponde ao total do Estado excluída apenas a RMSP. 
(2002:26) apontam que o rendimento familiar médio é mais alto e que a proporção de pobres é menor nas áreas classificadas como rural metropolitano do Canadá, comparativamente às áreas rurais e nos municípios com menos de 10.000 habitantes.

As possíveis explicações do resultado para a RMSP, de certa forma não esperado, residem em algumas características dos residentes rurais metropolitanos que os diferenciam dos não-metropolitanos e das famílias rurais não-agrícolas em geral.

Em comparação com os rurais que estão fora da RMSP, os metropolitanos são em média mais jovens e a taxa de ocupação é menor, fazendo supor que mais membros da família dedicam-se aos estudos, estando portanto fora do mercado de trabalho; por outro lado, as aposentadorias representam parcela bem menor do rendimento familiar para os rurais na região metropolitana (a metade de sua participação na área não-metropolitana), mesmo com maior presença de chefes não ocupados já que, entre estes, verifica-se menor proporção de aposentados (apenas 37\% dos chefes desocupados na RMSP recebem aposentadoria oficial, contra $55 \%$ nas área fora da região metropolitana); por último, maior proporção de famílias rurais na RMSP são chefiadas por mulheres, em comparação com as áreas rurais do resto do estado. Todos esses fatores contribuem para deprimir o rendimento familiar.

Mas a maioria dos fatores apontados é comum aos rurais metropolitanos e aos rurais não-agrícolas, como a estrutura etária e de ocupações, a formalização do emprego, a proporção de mulheres entre os chefes de domicílios e a escolaridade, e ainda assim os não-agrícolas situam-se em melhor patamar de renda e com menor grau de pobreza. O peso das aposentadorias e pensões na renda familiar per capita também é semelhante nos dois grupos (10,7\% para os rurais metropolitanos e $8,7 \%$ para os rurais não-agrícolas). As únicas diferenças mais fortes entre os dois grupos encontram-se na maior razão de dependência observada no rural metropolitano (especialmente devido à maior presença de membros das famílias com 65 anos ou mais) e na categoria "chefes não-ocupados": a proporção de não-ocupados entre os chefes de domicílios rurais na RMSP é maior (23,2\% contra $13,7 \%$ entre os não-agrícolas). Esses dois elementos poderiam explicar em parte a menor renda dos rurais metropolitanos.

Com o objetivo de confirmar os resultados encontrados para o ano de 2008, o estudo replicou a mesma pesquisa para 2004, a fim de validar as principais conclusões para 2008. Além disso, da comparação dos resultados para os dois anos é possível constatar tanto uma tendência geral positiva, para os indicadores estudados, incluindo o aumento da proporção de ocupados, do rendimento familiar real, da qualidade de vida, da formalização no trabalho, do nível de pobreza e da desigualdade de renda. 
Observando-se o comportamento desses indicadores por corte geográfico é possível, em geral, identificar uma tendência de equalização entre as condições do rural da RMSP e as demais áreas rurais do estado.

Em termos mais gerais, o trabalho aponta pistas para a investigação do papel da "integração rural-urbano" no desenvolvimento e bem-estar das famílias rurais. De um lado, já se encontra bem estabelecida a ideia das vantagens dessa integração, em termos do funcionamento dos mercados de trabalho (tende a reduzir-se a segmentação entre rural e urbano, com trabalhadores residentes no rural deslocando-se para trabalhos urbanos e vice-versa, com famílias que vivem em cidades trabalhando no campo) e pelo acesso dos habitantes rurais a mercados de produtos e a serviços de educação, saúde, benefícios sociais, entre outros (Gómez, 2001). Nessa situação, quanto mais próxima de um centro urbano estiver a localidade rural, mais intensa será a integração, sobretudo nos casos de urbanização dispersa, com muitas cidades de tamanho pequeno a médio permeando as áreas rurais. De outro lado, a manutenção do núcleo agrícola ao lado das atividades não-agrícolas (pluriatividade) parece constituir um importante elemento de elevação e estabilização da renda familiar, como já apontaram outros trabalhos (Kageyama, 2008; Schneider, 1999 e 2000). A inserção das famílias rurais no ambiente metropolitano, voltadas quase que exclusivamente a atividades não-agrícolas não representa uma real integração rural-urbano, mas apenas uma "justaposição" de domicílios classificados como rurais à área urbana metropolitana, sem usufruir de todas as vantagens dessa proximidade. Alguns benefícios como o acesso à educação e à água canalizada ou à carteira de trabalho assinada transbordam para o rural metropolitano, mas a "ruralidade" da família em torno da ocupação agrícola e da agricultura familiar está muito distante desse grupo. É cabível, a nosso ver, a conclusão de Figueroa (1997:13), segundo a qual a urbanização ajuda o desenvolvimento rural, "mas não qualquer urbanização e sim aquela geograficamente descentralizada.”

\section{Referências bibliográficas}

ARRAES, N. M.; ARONI, R. (2008). "Famílias pluriativas no rural metropolitano campineiro: uma situação em transição". In: Encontro ABEP. Campinas: ABEP.

BALSADI, O. (2008). Características do emprego rural no Estado de São Paulo nos anos 9o. [dissertação de mestrado]. Campinas: Unicamp.

CAMARANO, A. M.; ABROMOVAY, R. (1999). "Êxodo rural, envelhecimento e masculinização do Brasil: panorama dos últimos 50 anos". Texto para Discussão, n. 621. Instituto de Pesquisas Econômicas Aplicadas (IPEA). Brasília.

CAMPANHOLA, C.; GRAZIANO DA SILVA, J. [orgs.] (2004). O novo rural brasileiro. Brasília: Embrapa Informação Tecnológica. 
CROMARTIE, J. B. (2007). ERS-USDA Briefing Room Measuring Rurality What is Rural? URL [on-line]: <http://www.ers.usda.gov/briefing/rurality/ whatisrural/>. Acesso em: 02 de fev. de 2011.

CROMARTIE J. B.; SWANSON, L. L. (1996). “Census tracts more precisely define rural populations and areas”. Rural Development Perspectives, vol. 11 (3). URL [on-line]: <http://www.ers.usda.gov/publications/rdp/rdp696/rdp696e.pdf> Acesso em: 06 de fev. de 2011.

FIGUEIREDO, N. M. S. de; OLIVEIRA E SILVA, P. A. (2008). "Caracterização da população economicamente ativa, residente no meio rural na Região Metropolitana de Campinas". In: Congresso da SOBER. Rio Branco: SOBER.

FIGUEIREDO, N. M. S. de; BRANCHI, B. (2009). "Evolution of poverty and income distribution among Brazilian agricultural workers and families: an analysis by gender between 1992 and 2007”. In: FAO-IFAD-ILO. Workshop on Gaps, trends and current research in gender dimensions of agricultural and rural employment: differentiated pathways out of poverty. URL [on-line]: <http://www.fao-ilo.org/ fileadmin/user_upload/fao_ilo/pdf/Papers/16_march/Figueiredo_Branchi_final.pdf $>$.

FIGUEROA, A. (1997). "Hacia un nuevo enfoque sobre el desarrollo rural en América Latina”. In: Seminario Internacional Interrelación Rural-Urbana y Desarrollo Descentralizado. Taxco, México: FAO/ONU.

FONTANA, M.; PACIELLO, C. (2009). «Gender dimentions of rural and agricultural employment : differentiated pathays out of poverty: a global perspective». In: FAO-IFAD-ILO. Workshop on Gaps, trends and current research in gender dimensions of agricultural and rural employment: differentiated pathways out of poverty. URL [on-line]: <http://www.fao-ilo.org/fileadmin/user_upload/ fao_ilo/pdf/Papers/>.

GOMÉZ E. S. (2001). "Nueva ruralidad? Un aporte al debate". Estudos Sociedade e Agricultura, n. 17, p.5-32. Rio de Janeiro: UFRJ/CPDA.

HOFFMANN, R. (1998). Distribuição da renda: medidas de desigualdade e pobreza. São Paulo: Edusp. 275 p.

KAGEYAMA, A. (2008). Desenvolvimento Rural: conceitos e aplicação ao caso brasileiro. Porto Alegre: Editora da UFRGS.

MORRILL, R.; CROMARTIE, J.; HART, G. (1999). "Metropolitan, urban and rural commuting areas: toward a better depiction of the United States settlement system”. Urban Geography, vol. 20 (8), p. 727-748.

PASQUETTI, G. G. et al. (2009). "Meio ambiente e desenvolvimento na Região Metropolitana de Porto Alegre: notas introdutórias baseadas no espaço rural metropolitano”. In: X Salão de Iniciação Científica. Porto Alegre: PUC/RS. 
PLESSIS, V. du; BESHIRI, R.; BOLLMAN, R. D.; CLEMENSON, H. (2002). Definitions of «Rural». Agriculture and Rural Working Paper Series Working Paper, n. 61. Ontario: Statistics Canada, Agriculture Division. URL [on-line]: <http://www.statcan.gc.ca/pub/21-601-m/2002061/4224867-eng.pdf>. Acesso em: 04 de jan. de 2011.

PNAD (2004). Pesquisa Nacional por Amostra de Domicílios [Microdados CD]. IBGE.

PNAD (2008). Pesquisa Nacional por Amostra de Domicílios [Metodologia]. IBGE.

PNAD (2008). Pesquisa Nacional por Amostra de Domicílios [Microdados CD]. IBGE.

ROCHA, S. (1997). "Do consumo observado à linha de pobreza”. Pesquisa e Planejamento Econômico, vol. 27 (2), p. 313-352.

SANTOS, A. F. et al. (2004). “O rural da região metropolitana de Curitiba sob a ótica interdisciplinar: multidimensional e complexo”. Revista de Ciências Exatas e Naturais, vol. 6 (1).

SCHNEIDER, S. (1999). Agricultura familiar e industrialização: pluriatividade e descentralização industrial no Rio Grande do Sul. Porto Alegre: Ed. UFRGS.

SCHNEIDER, S. (2000). «A agricultura familiar em uma época de transformações: a pluriatividade como estratégia familiar de reprodução social». In: $X$ World Congress of Rural Sociology. Rio de Janeiro: IRSA.

SONG, Y. et al. (2009). "Feminization of agriculture and ageing of agricultural producers in rapidly changing China: policy implications and alternatives for equitable growth and sustainable development". In: FAO-IFAD-ILO. Workshop on Gaps, trends and current research in gender dimensions of agricultural and rural employment: differentiated pathways out of poverty. URL [on-line]: <http://www.fao-ilo.org/fileadmin/user_upload/fao_ilo/pdf/Papers/>. 
FIGUEIREDO, N. M. S.; BRANCHI, B. A.; KAGEYAMA, A. A.. Trabalhadores e famílias rurais...

\section{Anexos}

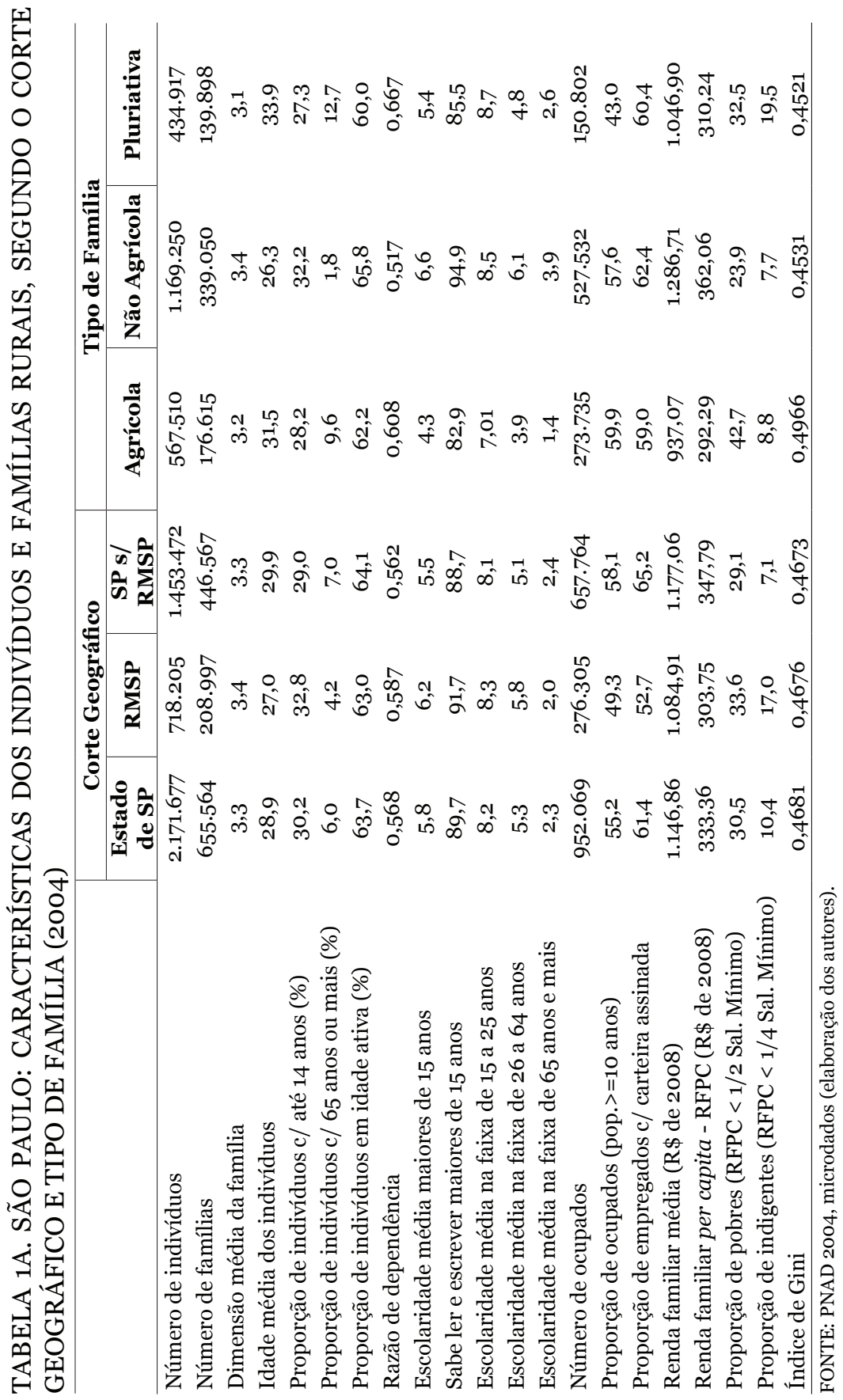




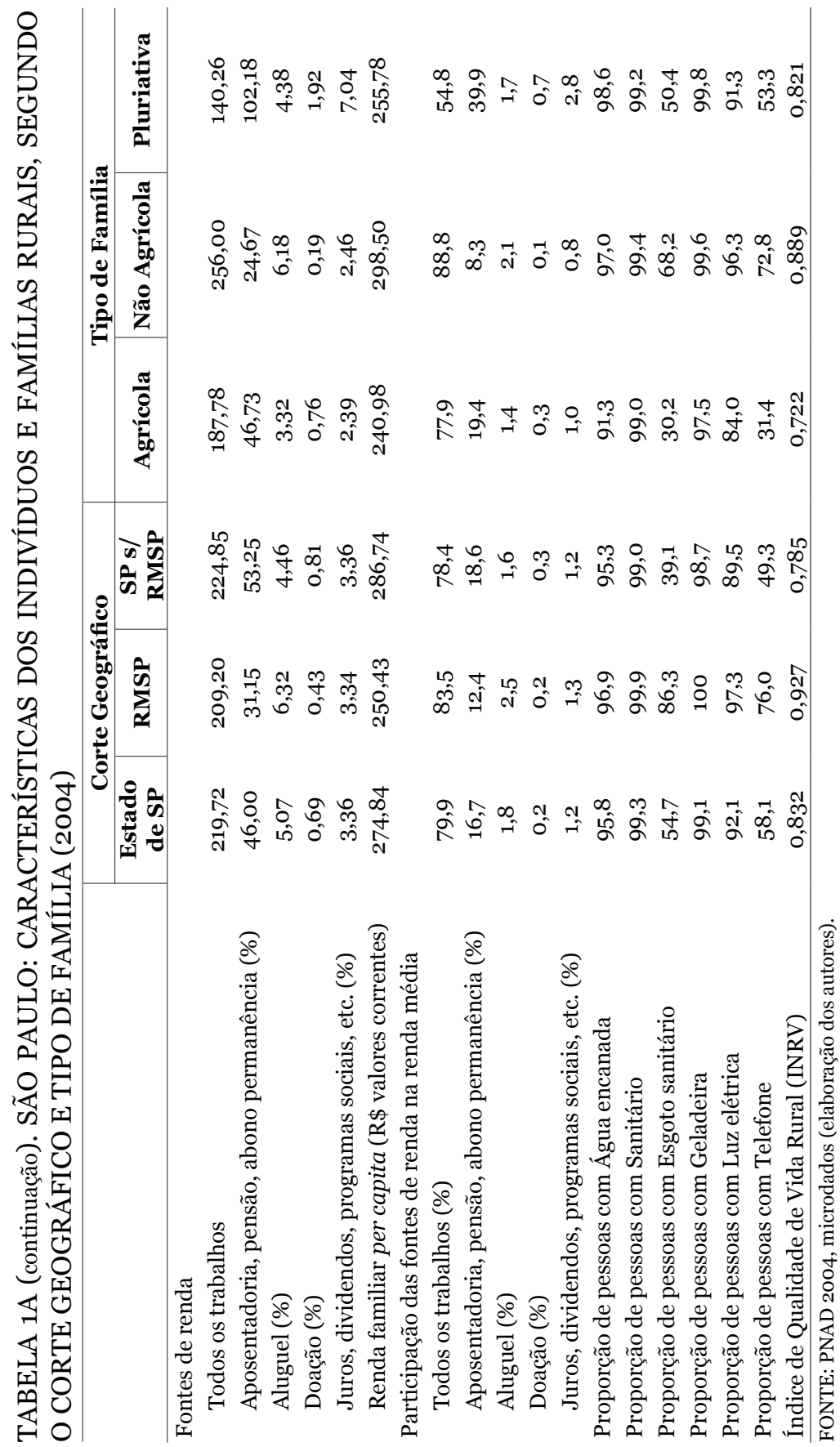


FIGUEIREDO, N. M. S.; BRANCHI, B. A.; KAGEYAMA, A. A.. Trabalhadores e famílias rurais...

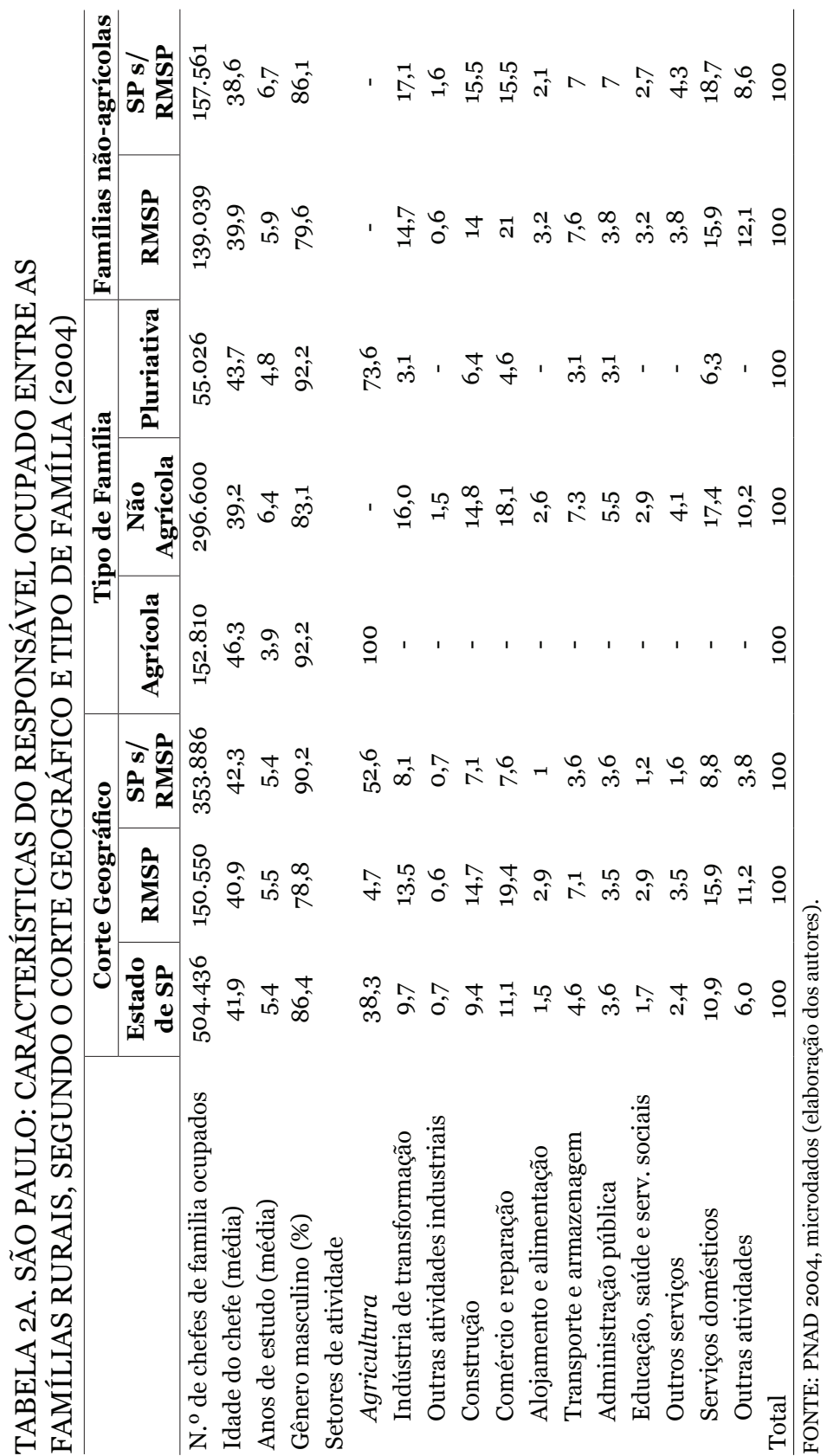




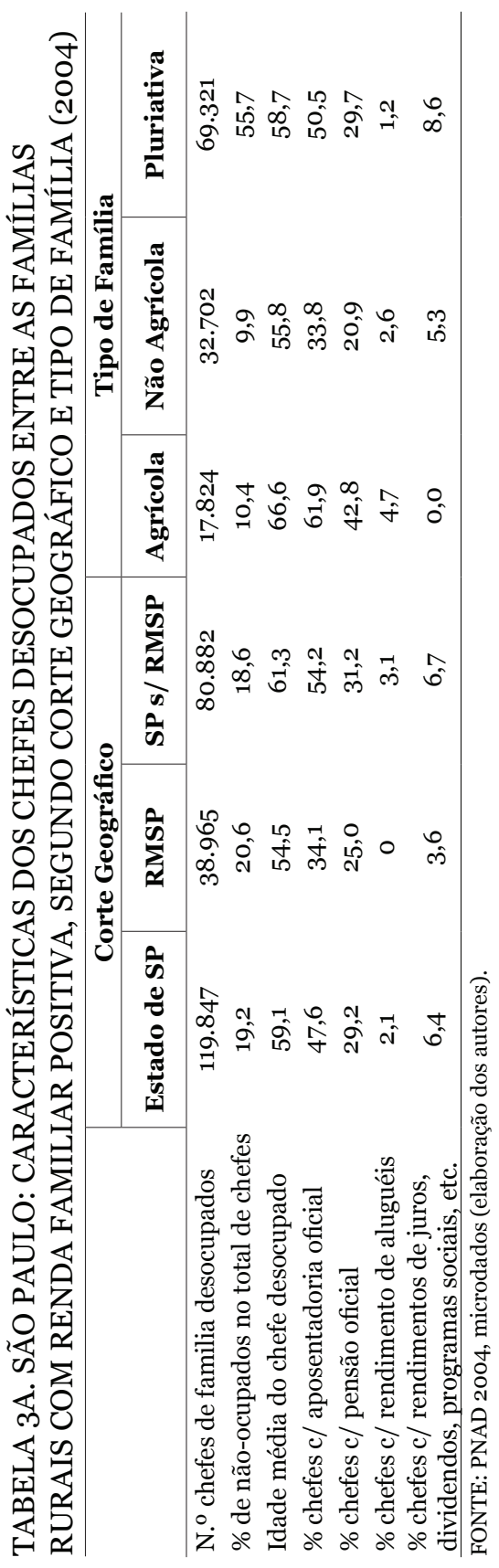


FIGUEIREDO, N. M. S.; BRANCHI, B. A.; KAGEYAMA, A. A.. Trabalhadores e famílias rurais...

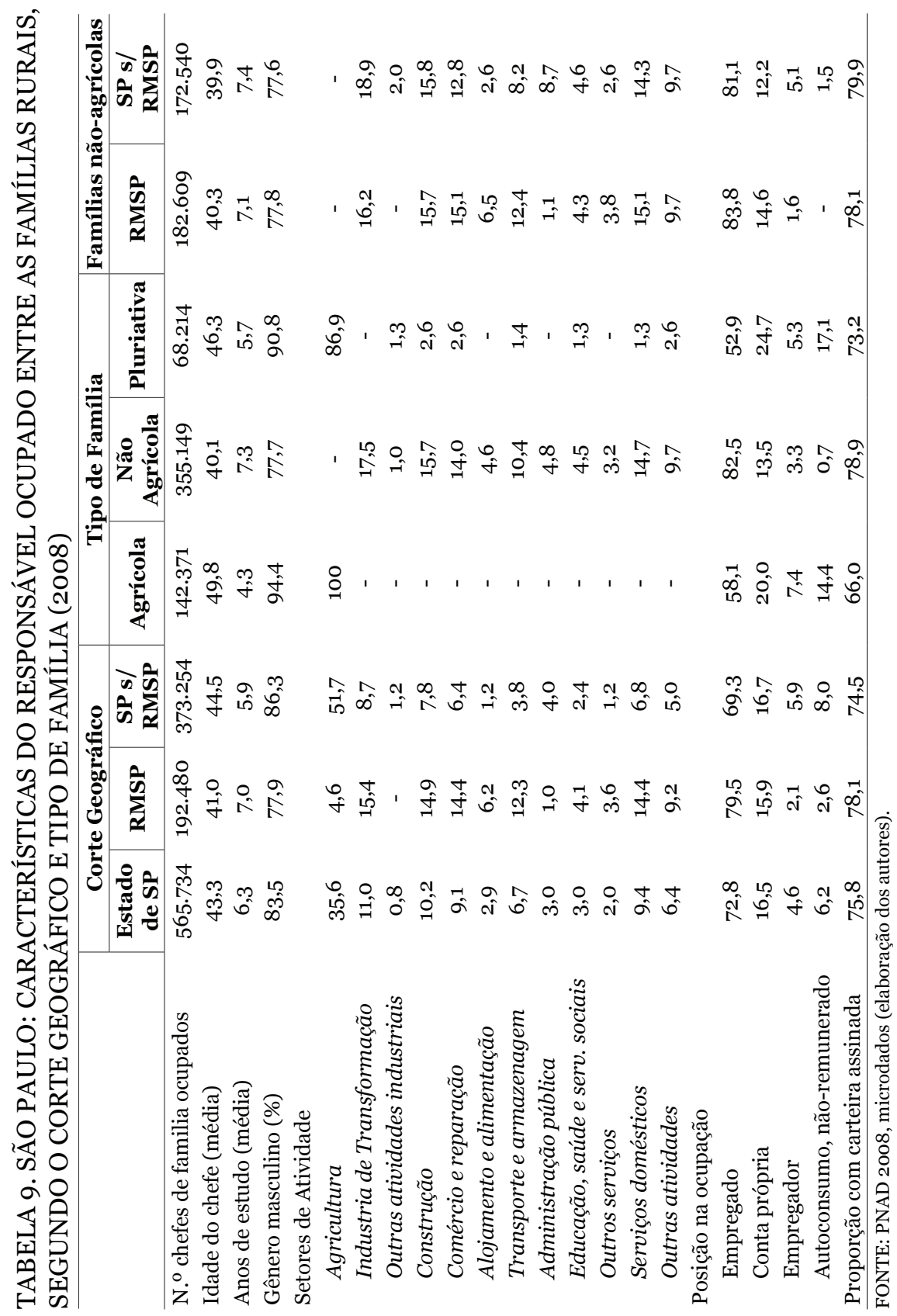


FIGUEIREDO, N. M. S.; BRANCHI, B. A.; KAGEYAMA, A. A. Trabalhadores e famílias rurais... 